\title{
A Proposed Administrative Strategy for Community Accountability Based on the Effective Schools' Quality Performance Standards in Jordan
}

\author{
Ziad Ahmed Twissi ${ }^{1,}$, , Ikhlaif Al-Tarawneh ${ }^{2}$ \\ ${ }^{1}$ War Child Organization UK, Jordan, Amman \\ ${ }^{2}$ Faculty of Education, University of Jordan, Jordan, Amman
}

Email address:

ziadtwissi@yahoo.com (Z. A. Twissi), ek_tarawneh@yahoo.com (I. Al-Tarawneh)

${ }^{*}$ Corresponding author

To cite this article:

Ziad Ahmed Twissi, Ikhlaif Al-Tarawneh. A proposed Administrative Strategy for Community Accountability Based on the Effective Schools' Quality Performance Standards in Jordan. Education Journal. Vol. 8, No. 3, 2019, pp. 125-133. doi: 10.11648/j.edu.20190803.16

Received: April 24, 2019; Accepted: May 28, 2019; Published: June 11, 2019

\begin{abstract}
The study aimed at developing a blueprinted administrative strategy for community accountability having regard to the effective schools' quality performance standards in Jordan. It was conducted on 90 heads of the educational councils in Jordan, who agreed to take part in the study during 2016 to 2017. The findings surfaced an urgent need for community accountability considering these standards from participants" view of points. Moreover, two domains of the community accountability scale; accountability responsiveness and incentives (rewards and penalties) were appeared at a critical level whilst eight domains; legislation, governance, accountability standards, resources, skills, and capacity building, planning and assessment, reporting and information sharing, as well as accountability ethics and morals, were revealed to be extremely urgent. Based on these results, it is found that an administrative strategy for community accountability based on quality standards of the schools' effective performance was developed, refereed and recommended to be applied over several stages of time. the new strategy for community accountability consists of five components: 1 . The overall framework of the strategy, 2. Planning for the implementation of the strategy, 3. Outreach and Capacity Building, 4. Practical and Operational Application, 5. Monitoring and assessment, and system responsiveness. Also, based on experts' judgment, all components of the strategy were highly acknowledged as relevant for the proposed strategy implementation.
\end{abstract}

Keywords: Administrative Strategy, Community Accountability, Quality Standards, Effective School

\section{Introduction}

Efforts have been made using miscellaneous means to increase participation in the education process and to develop community accountability in Jordan. However, the efforts have not been as fruitful as hoped. Citing Jordan's rank as reported in the World Bank's Global Governance Indicators Report (2014), the second annual report of the Ministry of Public Sector Development of Jordan (2016) underlined a declined level of accountability and participation in Jordan among the world's countries in 2014 compared to 2013. The decline was reflected in several educational indicators like the quality of education system, quality of mathematics and sciences, quality of school administration, Internet access in schools, as well as the availability of research and training services [1]. As per referring to the Human Development Report (2015) issued by the United Nations Development Program (UNDP), the Ministry's report pointed out that Jordan's ranking has dropped in the human development index from $77^{\text {th }}$ in 2014 to $80^{\text {th }}$ in 2015 . Overall, the report of the Ministry of Public Sector Development for human development (2017) indicated that Jordan has fallen six places in 2016 , ranking $86^{\text {th }}$ [2], which is definitely a very high rank and shows that how far the country is.

Appropriately, it has been examined that Jordan has seriously sought to find ways to ensure the development of accountability processes in education. Issuing the education quality and accountability system by the Ministry of Education in 2015 was a step in the right direction [3]. Despite the noteworthiness of the system as a technical 
system of educational accountability based on school-specific educational standards, the system did not furnish the community, educational councils as well as parents with any role to play in the accountability process [3].

Considering the failure of community accountability experiences in the Arab world and Jordan in particular, this study aimed at developing a proposed administrative strategy for community accountability based on the effective schools' quality performance standards in Jordan. In fact, this objective is in line with the need strongly recommended, by the National Human Resources Development Strategy (2015), to establish organizational structures that ensure the autonomy, authority and accountability mechanisms required to implement the human resources development strategy. Notably, the study places greater emphasis on the degree of need for an administrative strategy for community accountability, the identification of the appropriate strategy for community accountability and the extent to which this strategy is suitable for community accountability based on the effective schools' quality performance standards.

Thus, the proposed strategy through this research could be immensely valuable to the Ministry of Education in terms of developing accountability processes at the educational system level in a way that serves its orientation towards decentralization, and to the directorates of education as regards the development of positive relations with the local community, and the identification of responsibilities as well as roles to such a degree that offers the best technical and financial support to schools and teachers.

\section{Literature Review}

Accountability has been labelled using numerous terms. Examples of these terms include: administrative accountability, social accountability, media accountability, as well as community accountability that aimed at elevating the institutional performance, and advancing the educational system responsiveness to common needs by virtue of the involvement of local communities and non-governmental organizations (NGOs), which carried out by community monitoring and assessment or through community use of experts to measure the performance of public institutions, access to data, and participation in decision-making. According Al-Omari (2004), accountability refers to the duties and roles of officials, whether elected or appointed, managers, or employees, to provide periodic reports on the progress of work in the institution or the ministry so as to clarify their decisions and to interpret their policies, to illuminate the pros and cons, and to the extent of their success or failure in the implementation of their tasks [4].

In an education context, it is examined that the accountability processes went through several phases, shifting from inputs and processes-grounded accountability to results-based accountability [5]. Linn (2000) pointed out that the process of accountability has gone through five developmental periods focused on the use of tests and educational assessment for the purpose of education reform in the second half of the twentieth century, where students' tests are one of the most important tools [6]. In addition to this, Linn (2000) also pointed out that the priority in the 1950s was on progress tracking and comparison between schools. Furthermore, it is found that in the 1960s, accountability processes shifted to focus on questioning educational programs through the use of tests. The emphasis in the 1970s was turned to tests of minimum competencies and student achievement standards. The emergence of the accountability of education directorates was in the 1980s, in which attention has been paid to results-based performance. Finally, the accountability phase of the 1990s was based on standards and strict restrictions on accountability.

Until 2014, it is examined that educational accountability in Jordan remained restricted to the Education Law and its amendments. However, the accountability process is vested in the judicial and administrative authorities outside the educational system. The historical development of educational accountability in Jordan since the establishment of the Emirate can be classified into five stages in view of its association with the historical development of the educational legislation. These five stages are as follows (1) the schooling stage, which is based on the Ottoman system in the period before 1939. (2) The educational stage from 19391946, which included the principal event in the history of education in Jordan, the issuance of the first educational law. (3) The constitutional stage between 1939-1946, which included the drafting of the first draft of the constitution in 1946 and the promulgation of the amended constitution in 1952. (4) The education law stage from 1964-2003 that began with the issuance of the Education Law of 1964. No. 16 , which is a fundamental turning point in Jordanian education process? (5) The knowledge economy stage between 2003 and 2014, as the Ministry of Education, adopted the project of knowledge economy knowledge economy project, where educational appeared for the first time as a concept of the project [6].

Accountability and improvement of education stage [7]. At the beginning of 2013, the Ministry of Education realized the need to reconsider its strategic direction due to a large number of administrators in the ministry's center and the directorates of education, the shortage of teachers, and the high cost of the student compared to the low level of achievement as indicated by the results of international tests such as Trends in International Mathematics and Science Study (TIMSS) test [8], Program for International Student Assessment (PISA) test and the National Test [9], which required a new strategy for educational accountability, hence, the Ministry has established the Education and Accountability Unit in 2014.

Thus, the lessons learned from the Ministry of Education's implementation of its project towards the knowledge economy between 2003 and 2010 emphasized the importance of the role of the school as a crucial pillar for the development [10]. As of results, a team from the Jordanian Ministry of Education worked on developing a system of quality performance standards of the effective school in four 
key domains as can be depicted in Table 1 [3].

Table 1. Domains of the effective schools' quality performance standards.

\begin{tabular}{ll}
\hline Domains & Facets \\
\hline \multirow{2}{*}{ Teaching and learning } & Curriculum and teaching \\
& Student performance and assessment \\
& School focus \\
Student environment & Learning support \\
& Empowerment \\
School and community & Parents' participation \\
& Community participation \\
Leadership and Management & Leadership \\
& Management \\
\hline
\end{tabular}

Source: The Ministry of Education, Jordan (2015 a).

Community accountability was deemed as an essential tool for improving educational performance, pushing educational institutions to deliver quality services, boosting education cost management, increasing citizen satisfaction, and mobilizing community capacity in favor of educational institutions, in addition to the World Bank's (2005) rationale for improving governance, increasing the effectiveness of development and improvement, empowering local communities, promoting transparency, promoting fairness and integrity, reducing corruption and increasing trust between citizens and government to achieve cooperation against public challenges and threats to society and to achieve justice in the distribution of gains as well as services provided by the state to citizens, especially to remote and disadvantaged regions in the country [11].

There were numerous studies have been conducted on accountability processes. Dorn and Ydesen (2015), explored the common features and educational accountability prevalent in previous studies in the United States of America in order to identify future research directions in accountability. The study of Dorn and Ydesen (2015) revealed a positive relationship between educational accountability style and the purposes of education in some historical periods, the harmony of its organizational structure with the structure of the government, and accountability cannot operate in isolation from the community accountability that is the source of its authority, and access to educational institutions and management [12]. Additionally, accountability practices must meet the aspirations of education stakeholders; students and parents.

Arab Renaissance for Democracy and Development (ARDD) and the Norwegian Research Foundation (Fafo) (2017) carried out a study aimed at providing in-depth views on the challenges and gaps in accountability in the education system in Jordan and the relationship between the legal framework, decentralization, and governance. The study figured out large gaps in the accountability system, weak cooperation between the administrative levels in the Ministry of Education, and weak cooperation with the local community, parents and the civil society organizations [13]. The results also highlighted that the education system still suffers from the centralization of decisions and policymaking.
Concurrently, Twissi and Al-Tarawneh (2017) examined the implementation degree of educational accountability and its relation to administrative effectiveness in the Directorates of Education in Jordan from the perspective of the Heads of Departments using a sample consisted of 125 heads of departments in six directorates of education in Jordan [14]. The results of the study showed that the degree of application of accountability was good, while the degree of administrative effectiveness was very good, and that there is a positive correlation relationship between the degree of educational accountability and the degree of administrative effectiveness [14].

Moreover, in their qualitative study on the implementation and results of the accountability system, Marsh, Mecenas, and Hough (2017) build their analysis on data collected via interviews with 4 employees of accountability system team, 6 leaders, 29 managers, 15 school principals working at six education departments in the state of California. The authors also used 42 hours of observations of accountability team meetings. The study revealed a high level of participants' adoption of community accountability, as well as some challenges from the perspective of education managers, including the challenges of limited technological capabilities and some concerns about credibility [15].

Saleh Muqaddam, Mazloum, Sharafkhani, Gholami and Emadzadeh (2017) applied the classic Delphi method to a sample of experts in three stages, 30 experts in the first stage and 15 experts in both the second and third stages. Out of the 128 elements that could be used by policymakers and administrators to achieve community accountability objectives, 69 elements were regarded as critical ones for community accountability [16].

Copp (2019) conducted a study aimed to identify How teachers respond to external evaluation is "reactivity" which can gauge both the amount and type of instructional effects. Quantitative analyses were done to examine the prevalence of reactivity, and qualitative interview data were used to support the findings and to elaborate on relevant details. The results were that teachers generally do show reactivity to large-scale assessment data, yet this change tends to be more "teaching to the test." There is no consensus in the teaching community regarding assessment or accountability policies. These policies do not focus on teacher implementation practices needed to meet stated goals [20].

Finally, Tarhan, Karaman, Kemppinen \& Aerila (2019) conduct a research aimed to explores the characteristics of the teacher evaluation model in Finland. Highlighting the unique qualities of the Finnish case, also to compare these teacher evaluation practices with the increasingly applied value-added model (VAM) for teacher evaluation across the globe. the analysis revealed that the Finnish Model prioritizes teacher empowerment and professional development by carrying out bottom-up evaluation practices. With a clear focus on teacher empowerment and professional development, this framework substantially differs from accountability measures such as VAM, which emphasize rigid data collection procedures and the use of standardized 
test scores to hold teachers accountable based on their students' academic performance. This study also revealed that professional development endeavors of teachers are highlighted as the key elements in Finnish teacher evaluation in Finland [21].

The review of the previous studies illustrated that the focus of previous studies was to investigate the extent to which societal accountability was applied (Twissi and Al-Tarawneh, 2017), to identify gaps in the application of societal accountability [13], or to identify the factors of accountability [16]. On the contrary, the present study seeks to develop a strategy for community accountability based on specific criteria, rather than traditional systems already in place.

\section{Study Methodology}

The current study is described as developmental one in terms of its development survey design by reviewing the literature, designing the data flow map, formulating the strategy, and verifying the appropriateness of the strategy for the practical application. In order to ensure the proper use of this developmental design, the study adopted the following five stages: (1) review of literature related to accountability systems development and types, the relationship between governance and accountability, key elements of community accountability, and quality standards of the effective school performance. (2) building a matrix that interconnects each accountability type with its elements, principles, users, tools, and the most important sources of data to be referred to in the accountability processes. (3) collecting data on the degree of need for community accountability in light of the effective schools' quality performance standards from the perspective of the heads of educational councils in Jordan. (4) designing and implementing the steps of strategy development, as follows: (a) conducting a literature review in order to identify key concepts and elements of community accountability, rationale of community accountability, factors influencing community accountability, the relationship between community accountability, governance, improvement of education, change towards community accountability, and educational and quality performance standards of the effective school. (b) entry of the core elements within the proposed domains according to the classifications on which the instrument was built. (c) application of the study tool to identify the degree of need for accountability from the perspective of heads of educational councils in Jordan and collecting and analyzing data. (d) identification of the basic assumptions of the strategy based on the results and literature review of accountability. (e) a focus group of ten traditional accountability experts at the Ministry of Education was held to analyze the educational environment in terms of accountability strengths, weaknesses, threats and opportunities. (f) formulating the proposed strategy for community accountability in Jordan Based on the results of the literature review. (g) Validating the strategy using focus group discussions, observations, modifications as well as the results of participants' evaluations. (5) Production of the final strategy document [17].

\subsection{Study Population and Sample}

The population of this study comprised all the heads of educational councils in Jordan $(\mathrm{N}=342)$ according to the latest update of the records of the management of the Center for Training and Educational Supervision for the year 2015, as presented in Table 2 .

Table 2. Distribution of the study population by virtue of region and gender.

\begin{tabular}{lllllll}
\hline \multirow{2}{*}{ Region } & Male & \multicolumn{3}{c}{ Female } & Total \\
\cline { 2 - 7 } & $\mathbf{N}$ & $\mathbf{n}$ & $\mathbf{N}$ & $\mathbf{n}$ & $\mathbf{N}$ & $\mathbf{n}$ \\
\hline South & 77 & 26 & 6 & 5 & 83 & 31 \\
Center & 134 & 30 & 8 & 5 & 142 & 35 \\
North & 113 & 21 & 4 & 3 & 117 & 24 \\
Total & 324 & 77 & 18 & 13 & 342 & 90 \\
\hline
\end{tabular}

The study instrument was distributed to 255 members of the study population, i.e. $75 \%$ of the study population. A total of 90 questionnaires were returned bearing a $26.3 \%$ response rate.

\subsection{Study Instrument}

In this study, an instrument was developed to identify the degree of the need for community accountability in light of the quality standards of the effective school, according to the following steps: (1) identifying the domains of the instrument and its items in its primary form: In line with the literature, 10 domains were identified, the basic elements of community accountability were also established and drafted as measurable items. The primary form of the instrument encompassed 83 items. (2) validating the study instrument: The primary form of the instrument was validated by an expert panel $(\mathrm{n}=21)$ specialized in education from the Jordanian universities and employees responsible for accountability in the Ministry of Education. Furthermore, some of the items were moved from one domain to another, 23 items were deleted, and the content of some items was modified or reworded. The final scale was made up of 60 items. (3) instrument reliability: data were collected from 20 heads of educational councils not included in the study sample and analyzed using the Statistical Package for Social Sciences (SPSS) along with the coefficient of internal consistency (Cronbach's Alpha), as can be seen in Table 3 [18].

Table 3. Reliability statistics of community accountability scale.

\begin{tabular}{lll}
\hline No. & Domain & $\begin{array}{l}\text { Cronbach's alpha } \\
\text { coefficient }\end{array}$ \\
\hline 1 & Legislation & 0.81 \\
2 & Governance & 0.82 \\
3 & Accountability standards & 0.88 \\
4 & Resources & 0.78 \\
5 & Skills and capacity building & 0.79 \\
6 & Planning and preparing for assessment & 0.90 \\
7 & Reporting and information sharing & 0.86 \\
8 & Responding to accountability & 0.85 \\
9 & Incentives (penalties and rewards) & 0.77 \\
10 & Accountability ethics and morals & 0.88 \\
& Total & 0.94 \\
\hline
\end{tabular}




\subsection{Scale Rating}

Table 4 outlines a five-point scale anchored with (0)
"Low" to (4) "Critical" used to describe the degree of need for the administrative strategy for community accountability [18].

Table 4. Scale ratings of the need for the administrative strategy for community accountability.

\begin{tabular}{llllll}
\hline Estimation & Low & Little & Required & Urgent & Critical \\
\hline \multirow{2}{*}{ Intervals } & $0-<0.08$ & $0.8-<1.6$ & $1.6<2.4$ & $2.4<3.2$ & $3.24-4$ \\
& $20 \%$ & $40 \%$ & $60 \%$ & $80 \%$ & $100 \%$ \\
\hline
\end{tabular}

\subsection{Statistical Procedures}

In this study, a questionnaire-based survey was used to investigate the desired degree of community accountability. By the use of SPSS, Cronbach's alpha was measured to evaluate the internal consistency of the study instrument on the basis of a pilot sample consisted of 20 participants. On the other hand, means (M) and standard deviations (SD) was calculated in order to assess the extent of the need for the community accountability strategy from the perspective of the heads of educational councils in Jordan.

\section{Results and Discussion}

\subsection{Degree of Need for the Strategy of Community Accountability}

The results that have been obtained through the survey are shown in Table 5 related to the first question of the current research. The table indicated that the total need for the community accountability was urgent $(\mathrm{M}=2.8, \mathrm{SD}=0.59)$. Furthermore, it is obtained that the incentives (penalties and rewards) domain was the most critically needed one $(\mathrm{M}=$ $3.3,0.82)$, followed by responding to accountability $(\mathrm{M}=$ $3.21, \mathrm{SD}=0.78)$. The results pointed out that the other domains were urgently needed ( $\mathrm{M}$ ranged from 2.79 to 3.11 , SD ranged from 0.66 to 0.83 ).

The findings of incentives can be explained on assumptions related to the absence of incentives systems, the absence of linkage between the incentive system and accountability processes or its results. The system may exist, but there is a general sense of unfairness in its implementation. This may be due to the focus on bureaucracy rather than on results, or to administrative slackness and workers' lack of accountability. This often emphasizes the absence of incentives and responding to accountability. These domains do not meet the international goals and standards.

Table 5. Means and standard deviations of the need for the community accountability strategy.

\begin{tabular}{|c|c|c|c|c|c|}
\hline No & Domain & $\mathbf{M}$ & SD & Rank & Need estimation \\
\hline 9 & Incentives (penalties and rewards) & 3.3 & 0.82 & 1 & Critical \\
\hline 8 & Responding to accountability & 3.21 & 0.78 & 2 & Critical \\
\hline 4 & Resources & 3.11 & 0.71 & 3 & Urgent \\
\hline 7 & Reporting and information sharing & 3.11 & 0.78 & 4 & Urgent \\
\hline 6 & Planning and preparing for assessment & 3.05 & 0.73 & 5 & Urgent \\
\hline 2 & Governance & 3.05 & 0.66 & 6 & Urgent \\
\hline 1 & Legislation & 3.04 & 0.75 & 7 & Urgent \\
\hline 10 & Accountability ethics and morals & 2.95 & 0.83 & 9 & Urgent \\
\hline \multirow[t]{2}{*}{3} & Accountability standards & 2.79 & 0.75 & 10 & Urgent \\
\hline & Degree of need & 2.8 & 0.59 & & Critical \\
\hline
\end{tabular}

The need for other domains of community accountability (resources, reporting and information sharing, planning and preparation for assessment, governance, legislation, skills, and capacity-building, accountability ethics and morals, and accountability standards) has emerged urgently and is slightly less than the need for incentives and responding to accountability. This may confirm a real need to develop a community accountability strategy, as well as the weakness of human resources management related to accountability in terms of their choice and capacity building, and to improve the awareness of those concerned with accountability in terms of its objectives, mechanisms and its impact on achieving results.

The results pointed out that ethics and morals were urgently needed, which represent in fact a general shortcoming, even at the international level, because there were insufficient studies in this area that might require a further research. The need for accountability standards was also urgent and this may indicate a real need to review the system of standards, including the quality standards of the effective school, in order to update these standards so as to remain consistent with international standards. Finally, the degree of need for a community accountability strategy is urgent. In fact, this urgent degree is enough reason to develop an administrative strategy for community accountability based on the effective schools' quality performance standards in Jordan

\subsection{The Appropriate Administrative Strategy for Community Accountability}

On the basis of literature review, results of data analysis and results of the focus group, a five-component administrative strategy for community accountability was 
developed, which are discussed as follow

Component 1: The overall framework of the strategy:

The first component implies that on the strength of the results of the first question, which showed an urgent need for a community accountability strategy, and review of the literature, the assumptions on which the strategy was based was identified, the strategy justified, and the educational environment was analyzed to pinpoint strengths, weaknesses, opportunities as well as potential threats of the strategy.

A. The underlying assumptions of the strategy:

The strategy was built on three main assumptions: (1) there is no community accountability strategy in Jordan. (2) The strategy can be measured pursuant to its degree of acceptance by the members of the educational councils and by its benefits gained from the perspective of the experts at the ministry. (3) Strategy results can be systematically analyzed in the future using an assessment and follow-up program.

\section{B. Strategy justification:}

The rationale for developing the strategy can be summarized as follows (1) The low level of educational administrative accountability in general, which in turn affects the effectiveness of administrative performance in all educational administrative levels [13]. (2) The results of the students on the international tests (PISA - The Program for International Student Assessment and TIMSS - Trends in International Mathematics and Science Study) over the past 10 years have been lessening despite the Jordanian government's implementation of its ambitious project Towards Knowledge Economy [9]. (3) Jordanian education has been affected by the sudden increase in the number of Syrian refugees [19]. (4) High costs of the Ministry of Education activities and low funding due to the support of the Syrian crisis [19].

\section{Analysis of the educational environment:}

Analyzing the educational environment is a fundamental process of strategy development. Table 6 portrayed the results of educational environment analysis.

D. Objectives of the community accountability strategy:

The expected results of the Community Accountability Strategy were: (1) to reinforce the government's direction towards good governance, including integrity and transparency. (2) To pinpoint the common needs according to reality in order to promote the formulation of realistic educational policies. (3) To itemize Identify weaknesses and ways to treat them.

\section{E. Strategy elements:}

The strategy composed of a number of elements, which became visible with low degrees of practice in the answer to question one. The elements were categorized into 10 domains: policies and legislation, governance, standards of accountability, resources, skills and capacity building, planning and preparing for the assessment, information accessibility and sharing, reports, responsiveness, and incentives.

Component 2: Planning for the implementation of the strategy:

The second component implies that the planning process includes a number of significant and sequential steps: (1) Establishing a principal technical team capable of developing a strategic implementation plan that includes objectives and responsibilities, and a framework for evaluation and followup to ensure the achievement of the results. (2) Building team competencies in community accountability. (3) Forming subteams in order to develop procedural manuals for community accountability such as the Legislative Review Team, the Governance Review Team, the Procedural Evidence Guideline Team, the Incentive System Review Team, and finally, the Responsiveness Team to review the mechanisms of the Ministry's response to accountability reports.

Table 6. Analysis of the external and internal environment of community accountability in the Ministry of Education.

\begin{tabular}{|c|c|c|c|}
\hline $\begin{array}{l}\text { Strengths } \\
\text { An advanced data management system (EMIS) The } \\
\text { existence of a traditional accountability unit that } \\
\text { carries out the assessment process professionally. } \\
\text { Existence of competent and experienced human } \\
\text { resources in assessment. The existence of a system } \\
\text { of national standards that conforms to international } \\
\text { standards. The existence of an electronic network } \\
\text { covering most of the schools in Jordan. } \\
\text { Vision: Structured, results-oriented community accour } \\
\text { Opportunities } \\
\text { Government and community support for integrity } \\
\text { and transparency. Donors and supporters to } \\
\text { establish a community accountability system } \\
\text { Disorders of the region, increasing the opportunity } \\
\text { to export Jordanian human resources. }\end{array}$ & $\begin{array}{l}\text { Weaknesses } \\
\text { The presence of several bodies in the centre of the } \\
\text { ministry for evaluation and inspection. Lack of } \\
\text { community awareness of accountability processes, } \\
\text { objectives and relationship to power. Centralization } \\
\text { of the system and non-empowerment of workers in } \\
\text { the field. The instability of strategic directions due to } \\
\text { the continuous change in educational leaders. } \\
\text { tability } \\
\text { Threats } \\
\text { High level of expectations of the community from } \\
\text { the first moment of implementation. The number of } \\
\text { students increased significantly due to Syrian asylum } \\
\text { Some heads of educational councils focus on } \\
\text { personal interests, and regional. }\end{array}$ & $\begin{array}{l}\text { Internal } \\
\text { environment }\end{array}$ & $\begin{array}{l}\text { An efficient community } \\
\text { accountability system that } \\
\text { is fair, integrity and } \\
\text { transparent, able to support } \\
\text { the education system to } \\
\text { achieve its goals of } \\
\text { transforming schools into } \\
\text { learning communities, } \\
\text { raising graduation rates, } \\
\text { achieving the best } \\
\text { international standards, } \\
\text { and building capacity for } \\
\text { experts in accountability } \\
\text { processes that can be } \\
\text { invested regionally }\end{array}$ \\
\hline
\end{tabular}

Component 3: Outreach and Capacity Building:

In the third component, it includes building technical development programs and guides to define community accountability so that the educational and administrative leaders in the field and centre know the most important components of the social accountability strategy and its role in improving educational outcomes. This component includes a national strategy for public communication, and the definition of the responsibilities, rights, and obligations of applying community accountability.

Component 4: Practical and Operational Application As per according to the fourth component, the 
implementation of new programs and strategies in the educational sector is considered one of the most dangerous processes for its direct impact in the event of failure on a whole generation. Therefore, a number of important measures must be taken before and during the implementation process. Some of these measures are:

1. The applied primary examination or the codified calculated experimentation, in a part of the educational environment.

2. Documenting all phases of implementation from the beginning until the final stage of the generalization

3. Development of a specific mechanism for collecting feedback and making adjustments in an organized manner.

Component 5: Monitoring and assessment, and system responsiveness

As per according to fifth component, a framework for assessment, follow-up and a system responsiveness mechanism is required, as described below:

A. Assessment and follow-up framework:

It implies that the overall framework for assessment and follow-up contains the expected results achieved after the implementation of the strategy and the performance indicators for the overall assessment and follow-up framework.

B. System Responsiveness:

Accordingly, the system response processes are one of the most important outcomes of the community accountability process, which drives the system to achieve change in response to the detection of problems, weaknesses, and challenges posed by accountability processes. Response processes include the following key actions:
1. Keeping educational institutions and employees ready for community accountability at any time.

2. Ensure that reliable data and information are provided, together with evidence established by the accountability system.

3. Continuous and transparent dissemination of accountability reports.

4. Holding meetings under the leadership of the Supreme Leadership in the educational system to discuss issues of accountability with those concerned and putting the concerned parties under legal accounting according to the rules and regulations.

5. Relevant stakeholders should provide clarifications on reforms and changes taken in response to the Community Accountability Report.

6. The appeal of the provisions and decisions of community accountability must be made through the official channels specified by the system, so as to ensure impartiality and enable accountability to achieve the desired achievement.

\subsection{Degree of Relevance of the Proposed Strategy for Community Accountability}

Another focus group was held, in which three heads of educational councils with Ph.D. Three members of the Education and Accountability Unit of the Ministry of Education, including the former Head of the Unit, and four other Ministry of Education experts who are responsible for capacity building and educational supervision. Thus, the strategy was presented to them, and their responses were as shown in Table 7.

Table 7. The degree of relevance of the proposed strategy for community accountability.

\begin{tabular}{lll}
\hline Component & Mean of reviewers estimation & Notes \\
\hline First: The general framework of the strategy & $\% 95$ & Language revision \\
Second: Planning for the implementation of the strategy & $\% 88$ & Include the role of educational boards in planning \\
Third: Awareness and capacity building & $\% 98$ & There are no notes \\
Fourth: Practical and Operational Application & $\% 96$ & Empower councils to penalize defaulters \\
V Evaluation and Follow-up & $\% 100$ & There are no notes \\
\end{tabular}

On the basis of experts' judgment, all components of the strategy were highly acknowledged as relevant for strategy implementation. In addition to this, based on previous findings, the study recommends the following: (1) Developing an incentive system in the Ministry of Education and linking it to accountability processes and the career path of employees. (2) Developing a code of ethics and accountability that promotes transparency, integrity, and fairness and ensures the privacy of individuals. (3) Review legislation on community participation in planning, decision-making and accountability processes. (4) The study recommends that the Ministry of Education take the necessary measures to implement the community accountability strategy as developed in this study.

\section{Conclusion}

There are several efforts have been made in the Arab countries including Jordan in terms to increase the participation in the education process as well as to develop community accountability. However, it has been found that from the certain efforts were not much successful and the community accountability experiences in the Arab world including Jordan was not successful. In the light of such failure, this research intended to develop and proposed am administrative strategy for the accountability of the company based on the effective schools' quality performance standards in Jordan specifically. The overall aim of the research was in line with the necessity of strongly recommended human resource development strategy in order to develop an 
organizational structure that could make sure the autonomy, authority and accountability mechanisms through which the strategy can be implemented.

In order to accomplish the specified aim of the study, the researcher has adopted the development survey design approach, in which population comprises of all the heads of educational councils in Jordan. A survey was conducted by using survey questionnaire as an instrument to examine the level of the needs of the community accountability in light of the quality standards of the effective school. The collected data was analyzed by using a statistical tool, SPSS. However, from the results obtained from the analysis, it has been concluded that the total need for the community accountability has been found urgent. In addition to this, it has also been revealed that the incentives including both penalties and rewards domain have been identified as the most critically need of the community, which has been followed by responding to the community accountability. From the results of the study, it has been depicted that the other domains of the community accountability have also been needed on urgent basis.

Moreover, it has also been pointed out that the ethics and morals have also been needed on an urgent basis in the community, which represents in fact a general shortcoming, even at the international level. It is because there were many studies have been identified in the literature that has reported the need of conducting future research on the certain area of study. Based on the results obtained and the analysis of the previous results, all components of the administrative strategy for community accountability have been identified, which are relevant to the implementation of the study. Based on findings, it has also been recommended to develop an incentive system in the Ministry of Education and link it to the accountability processes and the career path of the employees. Furthermore, it has also been found that there is also a need to develop the code of ethics and accountability that could promote the transparency, integrity, and fairness and make the privacy of individuals. Along with this, it has also been found that there is also a need to review legislation on community participation so that the improvement can be brought in planning, decision-making and accountability processes and procedures. Finally, it has also been concluded that the Ministry of Education should take the necessary measures in order to implement the community accountability strategy, which is developed and proposed in through this research so that the positive change can be bought for the success of the entire community.

\section{References}

[1] Ministry of Public Sector Development. (2016). The most prominent international indicators and the reality of Jordan's situation. Second Annual Report. (8).

[2] Ministry of Public Sector Development. (2017). The most prominent international indicators and the reality of Jordan's situation. Third Annual Report. http://www.mopsd.gov.jo/en/PDF\%20Files/third\%20indicator \%20report.pdf (9).

[3] The Ministry of Education. (2015: a). a guideline of school accountability system. Unpublished guide. Ammaan Jordan. (13).

[4] Al-Omari, Haidar Barakat. (2004). The reality of educational accountability in the Ministry of Education in Jordan, unpublished doctoral dissertation, University of Jordan, Amman, Jordan. (1).

[5] Fuhrman, S. (1999). The new accountability. CPRE Policy Briefs, RB-27. Philadelphia, PA: The Consortium for Policy Research in Education. (4).

[6] Linn, R. L. (2000). Assessments and accountability. Educational Researcher, 23 (9): 4-16.

[7] The Ministry of Education. (2015: c). Education Quality and Accountability System, Ministry of Education, 2015. Jordan. http://www.pm.gov.jo/upload/attach/1453107942-pm-1. pdf(15).

[8] Provasnik, S., Malley, L., Stephens, M., Landeros, K., Perkins, R., and Tang, J. H. (2016). Highlights From TIMSS and TIMSS Advanced 2015: Mathematics and Science Achievement of U.S. Students in Grades 4 and 8 and in Advanced Courses at the End of High School in an International Context (NCES 2017-002). U.S. Department of Education, National Center for Education Statistics. Washington, DC. Retrieved 10 May 2017 from http://nces.ed.gov/pubsearch.(10).

[9] Samida, Hakima and Grace, Najwa (2014). Analysis of the results of international assessments TIMSS 2011 in the Arab States, Arab Organization for Education, Culture and Science.

[10] Harrison, Cameron. (2015). Driving up Quality of Education and Educational Outcomes: a national strategy. Unpublished paper. Jordan, Ministry of Education.

[11] The World Bank. (2005). Social Accountability Reference Guide: What Social Accountability Means for the World Bank.

[12] Dorn, S., \& Ydesen, C. (2015). Towards a comparative and international history of school testing and accountability. Education Policy Analysis Archives, 22 (115): 1-11.

[13] Arab Renaissance for Democracy and Development (ARDD) and the Norwegian research institute (Fafo). (2017). Fostering a Culture of Responsibility and Accountability Improving the Learning Environment in Jorda. A research Presented at Accountability and Quality of Education Workshop. Amman, Jordan.

[14] Twissi, Ziad Amed and Al-Tarawneh, Ikhlaif. (2017). Educational Accountability and its Relation to Administrative Effectiveness in the Directorates of Education in Jordan from the Perspective of the Heads of Departments. Jordanian Association for Educational Sciences, Jordanian Educational Journal, 2 (3): 78-101.

[15] Marsh, Julie; Mecenas, Susan Bush \& Hough, Heather. (2017). Learning From Early Adopters in the New Accountability Era Insights From California's CORE Waiver District. Educational Administration Quarterly.

[16] Salehmoghaddam AR, Mazloom SR, Sharafkhani M, Gholami H, Emami Zeydi A, Khorashadizadeh F, Emadzadeh A. (2017). Determinants of Social Accountability in Iranian Nursing and Midwifery Schools: A Delphi Study. IJCBNM. 5 (2), 175-187. 
[17] The Ministry of Education. (2016). Evaluation and follow-up of the school and directorate development program. (2012, 2013, 2014, 2015, 2016). Ammaan Jordan. http://www.moe.gov.jo/NewPages.aspx?PageID=YQ3uIWvks $\mathrm{gg}=$.

[18] Zikmund, W. G., Babin, B. J., Carr, J. C., \& Griffin, M. (2013). Business research methods. Cengage Learning.

[19] The Ministry of Education. (2015: b). Statistical reports for the years 2011-2015. http://www.moe.gov.jo/MenuDetails.aspx?MenuID=29.
[20] Tarhan, H., Karaman, A., Kemppinen, L., \& Aerila, J. (2019). Understanding Teacher Evaluation in Finland: A Professional Development Framework.Australian Journal of Teacher Education, $44 \quad$ (4). $\quad$ Retrieved from https://ro.ecu.edu.au/ajte/vol44/iss4/3.

[21] Copp, Derek. (2019). Accountability Testing in Canada: Aligning Provincial Policy Objectives with Teacher Practices. Canadian Journal of Educational Administration and Policy, $188,15-35$. 